\title{
Transcorpocinetismo Estético-Político: \\ O cotidiano do corpo trans e o dissenso nas minhas práticas em arte contemporânea
}

Aesthetic-political transbodykinetism:

The daily life of the trans body and the dissension in my practices in contemporary art

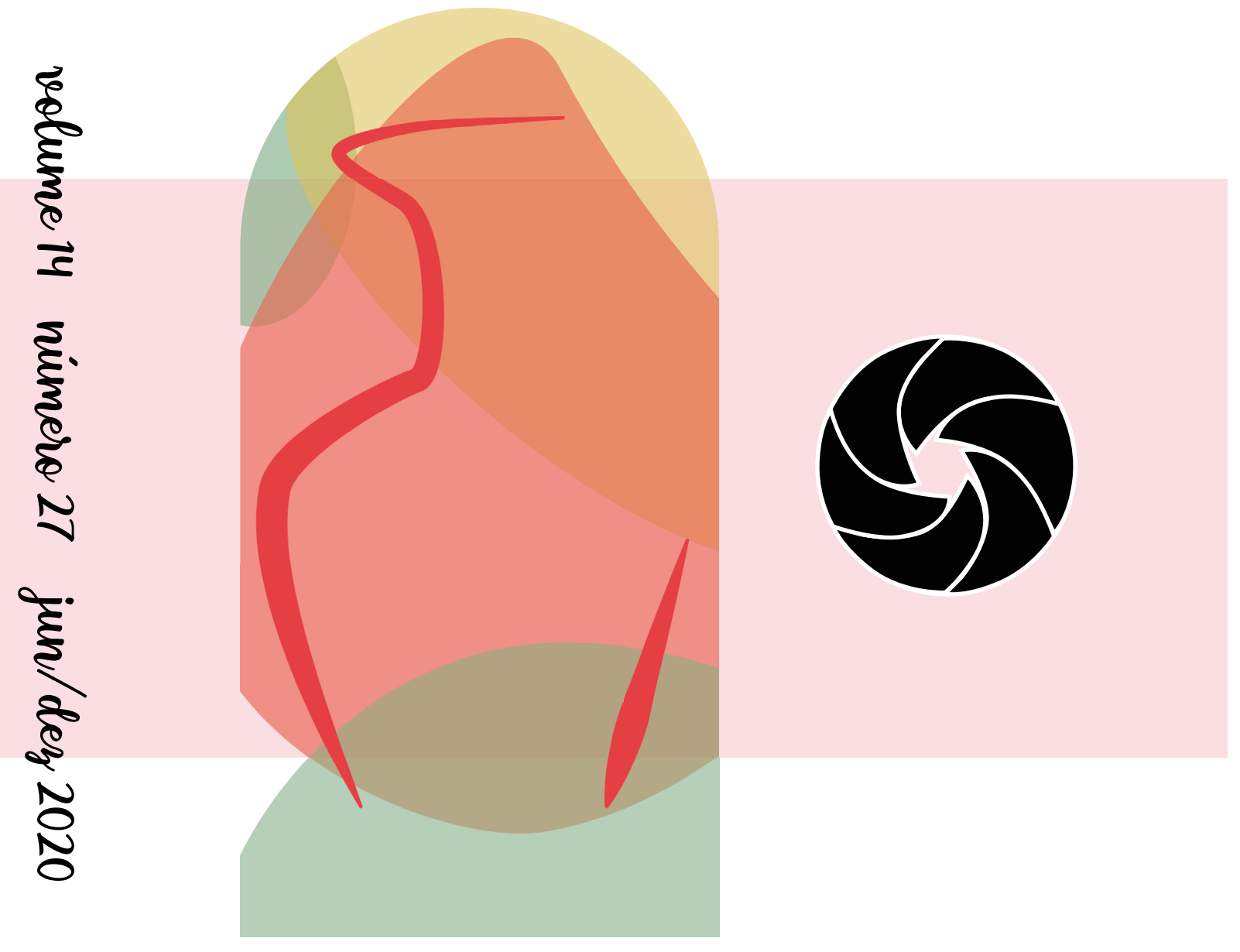

Brenda Gomes Bazante'

brendabazante@live.com

Cultura Material:

objetos, imagens e representacões - 1/2 


\section{RESUMO}

Este artigo faz parte da pesquisa "Cadê as travas transcorpocinéticas?", em andamento no Programa Associado de Pós-Graduação em Artes Visuais (PPGAV) UFPE/UFPB. Por meio de uma revisão de literatura, procura compreender como uma produção cinética, dentro do contexto da arte contemporânea, que retrate o corpo transgênero, as suas mudanças e seu cotidiano, pode causar dissenso. O referencial teórico será composto por Rancière (2012), Butler (2020), Preciado (2017) e outros. Esse estudo pretende ampliar as ligações teóricas entre os regimes da arte, segundo o primeiro autor, e os conceitos de performatividade e de contrassexualidade, respectivamente apresentados pelos dois últimos autores, a partir do processo criativo de uma escultura transcorpocinética. Além disso, busca encontrar caminhos investigativos para as práticas artísticas desenvolvidas no referido programa. Referências que serão orientadas pelas relações existentes entre 0 panorama teórico investigado, as intervenções estéticas e políticas de Indianara Siqueira nas suas aproximações com a pedagogia dos monstros de Cohen (2000) e, finalmente, as mudanças corporais vivenciadas por pessoas trans ao longo de suas vidas. Por fim, considera-se que essa investigação propõe um desdobramento dos regimes da arte e estimula a junção de seus caráteres poético/representativo, ético e estético, uma vez que tradicionalmente as mulheres trans não teriam sido devidamente contempladas pela produção escultórica, muito menos pela arte cinética.

Palavras-chaves: Arte Contemporânea; Dissenso; Representação do Corpo; Transexualidade.

\section{ABSTRACT}

This article is a part of the research "Where are the transbodykinetic tranny?" in progress in the Associate Program of Post-Graduate in Visual Arts UFPE/UFPB. Through a literature review it seeks to understand how a kinetic production, within the context of contemporary art, that portrays the transgender body, theirs changes and theirs daily life, can cause dissension. The theoretical framework will be composed by Rancière (2012), Butler (2020), Preciado (2017) and others. This study intends to expand the theoretical connections between art regimes, according to the first author, and the concepts of performativity and counter-sexuality, respectively presented by the last two authors, based on the creative process of a transbodykinetic sculpture. In addition, it seeks to find investigative paths for the artistic practices developed in the program. References that will be guided by the relations existing between the theoretical panorama investigated, the aesthetic and political interventions of the performer Indianara Siqueira in her approximations with the monsters pedagogy of Cohen (2000) and, Finally, the bodily changes experienced by trans people through theirs lives. Finally, it is considered that this investigation proposes an unfolding of the regimes of art and stimulates the combination of their poetic/representative, ethical and aesthetical characters, since traditionally trans women would not have been properly contemplated by sculpture production, much less by kinetic art.

Keywords: Contemporary Art; Dissension; Body representation; Transsexuality.
1 Mestranda em Artes Visuais pela UFPE, Pernambuco. Graduada em Licenciatura em Artes Visuais pela Universidade Norte do Paraná (2018), Especialista em Metodologia do Ensino de Artes pela Fac. de Educação São Luís, Maranhão. E-mail: brendabazante@ live.com. 
2 Quando emprego o movimento ligado ao corpo estou usando uma metáfora que simboliza as transformações graduais alcançadas por meio de cirurgias, tratamentos estéticos e hormonais nos corpos de mulheres trans/ travestis. Como se colocando lado a lado fotos de antes e depois destas intervenções pudesse ver estes corpos movimentando-se, como ocorre no processo de animação quadro a quadro, ou stop-motion, no qual desenhos com pequenas alterações criam a ilusão de movimento.

\section{Lá vêm elas, as Transcorpocinéticas}

Da junção das palavras "corpo trans" e "cinetismo", criei o vocábulo "Transcorpocinetismo" e suas praticantes serão chamadas de "pessoas transcorpocinéticas". Esse neologismo refere-se a um conceito que estou elaborando com a finalidade de relacionar as transformações feitas nos corpos de mulheres trans/travestis com o meu trabalho no campo da Arte Cinética. Essa ideia baseia-se na relação entre o movimento ${ }^{2}$ que ocorre tanto nos móbiles quanto na corporalidade trans ao longo do tempo, pois assim como construções artísticas móveis criam formas movimentando-se ao sabor do vento (BARRET, 1991), o corpo muda para satisfazer mudanças pessoais/corporais num dado intervalo temporal.

Juntamente com esse conceito, a Pesquisa "Cadê as Travas Transcorpocinéticas?", em desenvolvimento no Programa Associado de Pós-Graduação em Artes Visuais (PPGAV) UFPE/UFPB, pretende compreender como uma produção escultórica cinética que retrate 0 corpo transgênero e seu cotidiano, dentro do contexto da arte contemporânea, pode causar dissenso. Nesse artigo, o conceito de dissenso diverge daquele em que é visto como "o conflito de ideias e sentimentos" (RANCIÈRE, 2012, p. 59) e passa a ser encarado como "o conflito de vários regimes de sensorialidade" (Ibidem), ou seja, "uma singular forma de eficácia: a eficácia de uma desconexão, de uma rup- tura da relação entre as produções de habilidades artísticas e dos seus fins sociais definidos, entre formas sensíveis, significações que podem nelas ser lidas e efeitos que elas podem produzir (Ibidem).

Uma vez tomada essa decisão conceitual em conjunto com o objetivo acima descrito, senti a necessidade de relacionar, por meio desse artigo, as teorias que estabelecem os regimes de funcionamento da arte e da política, problematizando-os com os estudos de performatividade de gênero e de contrassexualidade, consequentemente, ampliando as discussões já realizadas sobre essa junção de temas. Para isso, elegi a revisão de literatura como metodologia e me apoiei em teóricos como Rancière (2012), Butler (2020) e Preciado (2017), bem como em seus comentadores. Tais autores ajudaram a encontrar caminhos investigativos e referências para as práticas artísticas desenvolvidas no referido programa, a partir das ligações estabelecidas nesse panorama teórico, das ações estético-políticas da militante/performer Indianara Siqueira, em suas relações com a pedagogia dos monstros de Cohen (2000), e da análise das transformações/performatividades presentes nos corpos de pessoas trans.

Dito isso, inicio tal empreitada com uma reflexão que procura tensionar as questões dissensuais, a partir de sua relação com a funcionalidade da arte contemporânea e a definição de política que, segundo Rancière, "ocupa-se do que se vê e do que se pode dizer sobre o 
que é visto, de quem tem competência para ver e qualidade para dizer, das propriedades do espaço e dos possíveis do tempo" (2009, p. 17). Além disso, o autor ainda destaca que:

\section{Política não é, em primeiro lugar, exercício do poder ou luta pelo poder. Seu âmbito não é definido, em primeiro lugar, pelas leis e instituições. A primeira questão política é saber que objetos e que su- jeitos são visados por essas instituições e essas leis, que formas de relações definem propriamente uma comuni- dade política, que objetos essas relações visam, que sujeitos são aptos a designar esses objetos e a discutí-los (RANCIÈRE, 2012, p. 59).}

Juntamente com essa definição, Rancière (2012) também defende que a arte, no modelo de eficácia estética, une-se à política através do dissenso. Entretanto, ele, ao analisar e aproximar alguns paradoxos existentes nesses dois campos, arte e política, critica algumas formas como os artistas pós-modernos têm se empenhado para atuar de forma "política" através de suas práticas. Para o autor, essa diversidade de propostas revela incertezas e operam a partir de um modelo de eficácia no qual "a arte é considerada política porque mostra os estigmas da dominação, porque ridiculariza os ícones reinantes ou porque sai dos seus lugares próprios para transformar-se em prática social" (RANCIÈRE, 2012, p. 52). Sendo assim, estas práticas estariam erro- neamente supondo, segundo o filósofo, "que a arte nos torna revoltados quando nos mostra coisas revoltantes, que nos mobiliza pelo fato de mover-se para fora do ateliê ou do museu, e que nos transforma em oponentes do sistema dominante ao se negar como elemento desse sistema" (RANCIÈRE, 2012, p. 52).

Em seguida, o pensador situa suas críticas nas estratégias artísticas em torno de questões como capitalismo tardio, por exemplo, e defende que os artistas contemporâneos "continuam a validar em massa modelos de eficácia da arte que talvez tenham sido abalados um século ou dois antes de todas essas novidades" (RANCIÈRE, 2012, p. 52-53). Nesse ponto começo a contextualizar essa crítica aproximando-a das representações de mulheres trans ao longo da História da Arte, pois não percebi, nos exemplos citados pelo autor, a presença de visualidades relativas à transgeneridade. Logo, me pergunto: ainda cabem representações de pessoas trans nos regimes ético e representativo? O quanto esses regimes podem contribuir com o aumento da visibilidade desses corpos dissidentes?

Ao contrário de Rancière (2012) que aparentemente nos ofereceu práticas artísticas protagonizadas por pessoas cis ou delas tratando, Berbara e Fonseca (2012) apresentam vestígios e detalhes de representações pertencentes às pessoas andróginas ou hermafroditas ao longo da história. Entre eles estão Luís XIV, Andy Warhol, Marcel Duchamp e até mesmo o Faraó Akhenaton. Observando esses nomes e outros 
Disponível em: https://parkstone.international/2015/10/15/jenny-saville-bares-all/

4 Expressão de gênero é "a forma como a pessoa se apresenta, sua aparência e seu comportamento de acordo com expectativas sociais de aparência e de comportamento de um determinado gênero. Depende da cultura em que a pessoa vive" (JESUS, 2012, p. 24). citados no levantamento que esses autores realizaram, percebo que, em sua caminhada histórica em busca da arte que retratou pessoas transgêneras, os estudiosos passaram pela Arte Egípcia, Grega, Romana e pelos movimentos artísticos europeus dos séculos XVI, XVII, XVIII, XIX e XX apresentando desde esculturas até encartes de propaganda. Chegando à contemporaneidade, eles consideram que:

Em uma época na qual a reconstrução genital, pela primeira vez na história, é medicamente viável, a cultura visual contemporânea parece aproximar-se com ainda maior vigor da longa e variada representação do hermafroditismo e da androginia na história da arte (BERBARA; FONSECA, 2012, p. 13).

Figura 1 - Passage. Jenny Saville. Óleo sobre tinta, 336 × $290 \mathrm{~cm}, 2004$.

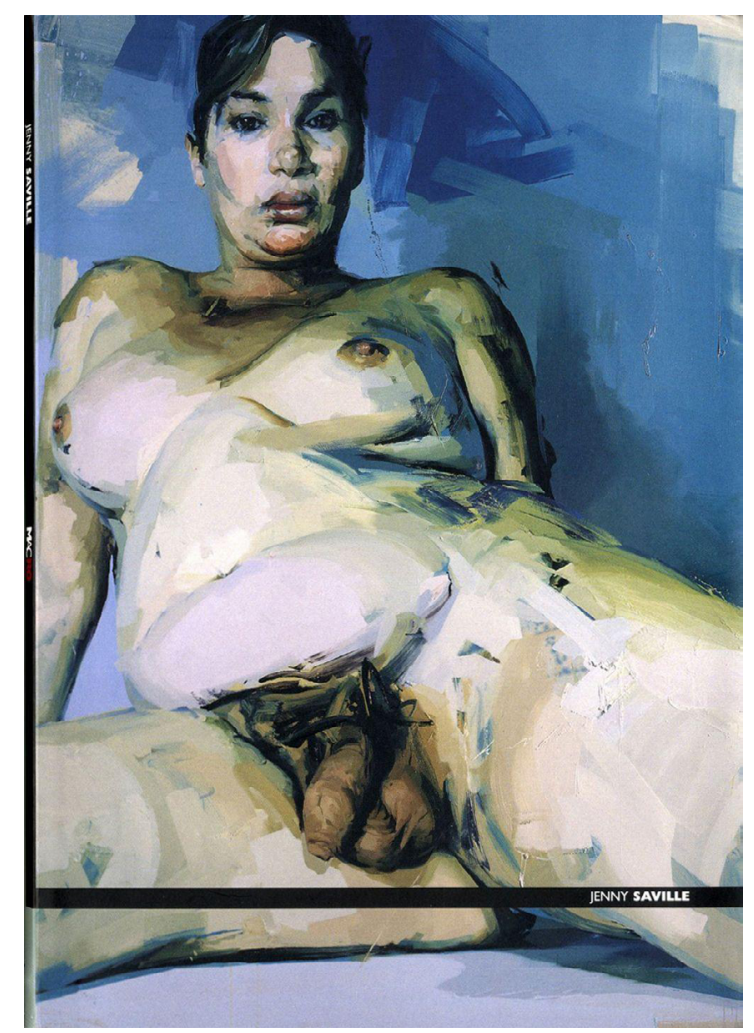

Fonte: Parkstone International. ${ }^{3}$
Entretanto, essa afirmação e os exemplos usados pelos autores acima citados não são suficientes para a problematização que inicio neste estudo, apesar da clássica escultura "O Hermafrodita Dormindo", de autoria desconhecida, constar na sua lista. Dados os objetivos que pretendo alcançar, a pintura "Passage", de Jenny Saville, (Figura 1), é um exemplar bem mais adequado aos questionamentos que proponho começar. Digo isso baseada na diferença que existe entre as obras mencionadas por Berbara e Fonseca (2012), em sua maioria homens gays e heterossexuais representados ou apresentando-se com expressões de gênero femininas ${ }^{4}$, e o quadro de Saville. Ao pintar a nudez de sua modelo, ela rompeu a invisibilidade que historicamente tentou apagar a existência dos corpos das pessoas trans, apresentando no mesmo corpo tanto um pênis quanto um par de seios. Para constatar essa ausência de corporalidades dissidentes de gênero na História da Arte, basta dar uma rápida olhada em grandes referências desse campo, como Gombrich (2013), Argan (1993), Archer (2012) e Krauss (1998). Em comum, todos eles têm o seguinte: a ausência de visualidades que retratem corpos transgêneros, mesmo Archer (2012) tendo discutido questões de gênero no capítulo sobre ideologia, identidade e diferença.

Os estudos de Butler (2020) e Preciado (2017) refletem sobre os motivos desse apagamento e sobre as discussões em torno da problemática de gênero. No decorrer 
desse texto eles serão devidamente apresentados enquanto relaciono- os com o conceito de dissenso, que a partir de agora começo a tensionar. Tenho em mente as dificuldades que se desenham no horizonte desta investigação, afinal, como bem aponta Mayrink (2015) em suas considerações sobre as dificuldades metodológicas enfrentadas na aproximação entre as teorias de Rancière e a transexualidade. Sobre esses desafios, a escritora relata o seguinte:

\section{Com uma maneira bastante própria de escrita e um jei- to único de colocar quase todos os seus conceitos em metáforas, Rancière nos con- vida ao seu universo, no qual fala fluentemente em uma língua na qual temos conhe- cimentos parcos. Os concei- tos são desenvolvidos intei- ramente, mas particionados em inúmeros textos, sendo preciso pinçá-los para obter uma imagem completa das analogias feitas (MAYRINK, 2015, p. 105).}

Ciente desses percalços, me aventuro nessa jornada teórica partindo dos regimes de arte, aqueles que Rancière (2012), em sua análise, mantêm afastados constantemente, para, posteriormente, me dirigir à difícil tarefa de propor a mescla de dois deles (representativo e estético ou pedagógico e estético), considerando para isso que os corpos trans são dissensuais por excelência. Esse argumento baseia-se no rompimento com os padrões de gênero e comportamentos espera- dos de uma pessoa que, por exemplo, nasceu com a genitália considerada masculina. Identificando-se enquanto mulher trans, ela passa a expressar o gênero feminino, e, em muitos casos, não apenas nos gestos, mas através de alterações nas esferas cirúrgicas, endocrinológicas ou estéticas. Em minha pesquisa, essa ruptura, que se manifesta nas questões de gênero, passa para 0 campo das artes e é ampliada ao utilizar a Arte Cinética, historicamente abstrata, como linguagem escultórica na construção de um móbile. Esse objeto, seus esboços e protótipos, apresentados neste artigo, darão conta de retratar um torso que contenha, assim como o quadro "Passage", um pênis, um par de seios e um quadril arredondado. Características comuns a transfeminilidades que não realizam a cirurgia de transgenitalização ${ }^{5}$.

As corporalidades redesignadas por esta cirurgia não interessam ao estudo aqui realizado, pois elas, visualmente, assemelham-se às transfeminilidades cisgêneras. $\mathrm{Na}$ perspectiva da junção de regimes que exercito, o dissenso cessa após esse procedimento. Para a existência do dissenso como proponho, é preciso haver ambivalência de gêneros de acordo com os padrões socialmente estabelecidos, ou seja, é necessário que no mesmo corpo coexistam, por exemplo, pênis e seios para mulheres trans, ou peitoral e vagina para homens trans. Coexistências que divergem do binário: homem-pênis e mulher-vagina.

Uma parte considerável da população LGBTIAP+ enquadra-se
${ }^{5}$ A cirurgia de transgenitalização é um "procedimento cirúrgico por meio do qual se altera o órgão genital da pessoa para criar uma neovagina ou um neofalo. Preferível ao termo antiquado 'mudança de sexo'. É importante, para quem se relaciona ou trata com pessoas transexuais, não enfatizar exageradamente 0 papel dessa cirurgia em sua vida ou no processo transexualizador, do qual ela é apenas uma etapa, que pode não ocorrer" (JESUS, 2012, p. 30). 
nesse corpo dissidente e vive num País que é um dos que mais mata pessoas trans no mundo. Infelizmente, mesmo com o aumento das discussões sobre transexualidade, a grande parte da população se mantém preconceituosa e faz vista grossa para questões de transgeneridade. Sob esta perspectiva, imaginemos uma mulher trans, com baixa ou média passabilidade, caminhando num shopping de qualquer cidade. Ela certamente atrairia a atenção das pessoas que inevitavelmente começariam a fazer a "terrivel" pergunta: é um homem ou uma mulher? Na dúvida, o dissenso se instaura, pois esse corpo se desconecta daquilo que os olhos e a mente dos espectadores esperavam, daquilo que Ihes foi ensinado ao logo dos anos. Sobre essa experiência, Foucault (2013) oferece um relato semelhante. Enquanto discute corpos utópicos e heterotopias, o autor diz o seguinte:

Corpo incompreensível, corpo penetrável e opaco, corpo aberto e fechado: corpo utópico. Corpo absolutamente visível, em um sentido: sei muito bem o que é ser olhado por alguém da cabeça aos pés, sei o que é ser espiado por trás, vigiado por cima dos ombros, surpreso quando percebo isso, sei o que é estar nu; no entanto, este mesmo corpo que é tão visível, é afastado, captado por uma espécie de invisibilidade da qual jamais posso desvencilha-lo (FOUCAULT, 2013, p. 10).
Estabelecido este panorama, imaginemos uma escultura que ao mover-se representa esse corpo, mas agora ele não está mais vestido e sim despido. Será que o questionamento e o dissenso permanecerão? Eles serão "maximizados" pela nudez da peça? O que as pessoas achariam de uma escultura como essa? Ela representa o que se espera de um objeto de Arte Cinética? Ao contemplá-la, as pessoas passariam a entender um pouco mais sobre a transexualidade? Estaria a artista que a produziu reproduzindo modelos de eficácia da arte abalados e superados a centenas de anos atrás?

Essas perguntas norteiam 0 presente estudo a partir deste ponto. Elas o orientarão em busca da compreensão, inicial, acerca da possibilidade de ruptura momentânea dos regimes de arte quando aproximados das problemáticas de gênero e da contrassexualidade. Desconexão que visa, por hora, examinar se é possível, por meio de uma escultura cinética, experimentar, conjuntamente, poética/representação, ética e estética, ou apenas uma e outra. Conectar, tensionar ou adaptar, na observação da representação de um corpo trans em movimento, esses conceitos tão distintos que aqui se unem na tentativa de ajudar a aumentar a visibilidade de corporalidades a muito invisibilizadas. 


\section{Ético, Mimético/Poético, Estético, Performático e/ou Contrassexual}

O regime ético da arte obedece a certas regras relacionadas à função que as imagens exercem, o seu destino e as verdades por elas defendidas. Trata "de saber no que o modo de ser das imagens concerne ao ethos, à maneira de ser dos indivíduos e das coletividades" (RANCIÈRE, 2009, p. 29).

Separado desse modelo, o regime poético/ representativo identifica a arte no duplo poieses/ mimesis. Nesse sistema o mimético diz respeito a um grupo de práticas artísticas que elaboram imitações ordenadas por uma série de regras específicas, nas quais

\section{As imitações podem ser reco- nhecidas como pertencen- do propriamente a uma arte e apreciadas, nos limites des- sa arte, como boas ou ruins, adequadas ou inadequa- das: separação do repre- sentável e do irrepresentá- vel, distinção de gêneros em função do que é representa- do, princípios de adaptação das formas de expressão aos gêneros, logo, aos temas re- presentados, distribuição das semelhanças segundo prin- cípios de verossimilhança, conveniência ou correspon- dência, critérios de distinção e comparação entre as artes etc (RANCIÉRE, 2009, p. 31).}

Um terceiro regime diverge rigorosamente do ético e do poético. Essa diferença ocorre quando ele "identifica a arte no singular e desobriga essa arte de toda e qualquer regra específica, de toda hierarquia de temas, gêneros e artes" (RANCIĖRE, 2009, p. 33-34). O Regime Estético rompe com a identificação da arte por meio de suas formas de fazer e foca nas questões da sensibilidade próprias às práticas artísticas, ou seja, ele se opõe diretamente aos regimes representativo e ético. Então, "significa propriamente a eficácia da suspensão de qualquer relação direta entre a produção das formas da arte e a produção de um efeito determinado sobre um público determinado" (RANCIÉRE, 2012, p. 58).

Essa ruptura característica do regime estético e de sua eficácia consiste na "suspensão de qualquer relação determinável entre a intenção do artista, a forma sensível apresentada num lugar de arte, o olhar do espectador e um estado de comunidade" (RANCIÈRE, 2012, p. 57). Aspectos criticados pelo autor como práticas há muito tempo superadas. No entanto, me pergunto se essas produções fossem inspiradas por questões ligadas às questões de dissidência de gênero, ou seja, de problemas enfrentados pela população transgênera, elas seriam tão superadas assim? Será que o regime ético, no seu papel de relacionar imagens e formas de vida, estimula a compreensão das subjetividades essa comunidade? $\mathrm{E}$ as artistas travestis seriam aptas a criar reproduções de seus corpos de acordo com as regras do regime poético? Que linguagens seriam adequadas a estas imitações? Será que eu, enquanto artista transexu- 
Ideologia, resultante do binarismo ou dimorfismo sexual, que se fundamenta na crença estereotipada de que características biológicas relacionadas a sexo são correspondentes a características psicossociais relacionadas a gênero. $O$ cissexismo, ao nível institucional, redunda em prejuízos ao direito à auto-expressão de gênero das pessoas, criando mecanismos legais e culturais de subordinação das pessoas cisgênero e transgênero ao gênero que lhes foi atribuído ao nascimento. Para as pessoas trans em particular, o cissexismo invisibiliza e estigmatiza suas práticas sociais (JESUS, 2012, p. 28).

Heteronormatividade e a crença na heterossexualidade como característica do ser humano "normal". Desse modo, qualquer pessoa que saia desse padrão é considerada fora da norma, o que justificaria sua marginalização (JESUS, 2012, p. 29).

al, devo produzir obras que, assim como o Torso de Belvedere, na análise de Winckelmann, separam-se da minha essência, daquilo que sou, da minha subjetividade e de minha corporalidade? Qual o meu papel enquanto artistas trans, afinal?

Debruço-me sobre estas perguntas ao mesmo tempo em que considero a importância do regime estético nas reflexões em torno da emancipação do espectador. Porém, me arriscarei a iniciar as relações com as teorias de gênero partindo de três palavras que Rancière (2012) usou nas críticas ao modelo de eficácia pedagógica, são elas: "dominação", "ícones reinantes" e "prática social". Estes temas são discutidos, por vezes, com nomes diversos, nas obras de Butler (2020) e Preciado (2017). Ao longo de seus escritos, os pensadores iluminam essa caminhada que acabo de desencadear deixando claro que:

\begin{abstract}
Se o gênero ou o sexo são fixos ou livres, é função de um discurso que, como se irá sugerir, busca estabelecer certos limites a analise ou salvaguardar certos dogmas do humanismo como um pressuposto de qualquer análise de gênero (BUTLER, 2020, p. 30).
\end{abstract}

Seguindo o mesmo caminho, Preciado (2017) acrescenta ainda mais profundidade à associação entre "dominação", "ícones reinantes" e "práticas sociais" com as discussões sobre sexo/gênero ao examinar o sexo como tecnologia biopolítica. Para ele

\begin{abstract}
O sexo é uma tecnologia de dominação heterossocial que reduz o corpo e as zonas erógenas em função de uma distribuição assimétrica de poder entre os gêneros (feminino/masculino), fazendo coincidir certos afectos com determinados órgãos, certas sensações com determinadas reações anatômicas (PRECIADO, 2017, p. 25).
\end{abstract}

Continuando seu exame das estruturas dominantes representadas pelo cissexismo6, que é reafirmado/corroborado pela heteronormatividade7, Butler (2020, p. 30) defende que "tais limites se estabelecem sempre nos termos de um discurso cultural hegemônico, baseado em estruturas binárias que se apresentam como linguagem da racionalidade universal". Trata-se de dispositivos opressores das existências transgêneras, que acabam desobedecendo essas regras ao transformar suas corporalidades em busca da adequação à identidade trans. Contudo, é preciso deixar claro que essa "adequação" ainda ocorre seguindo um padrão de corpo feminino normatizado que não é alcançado, pois estas estruturas de dominação não reconhecem esse corpo alterado como feminino. Sendo assim, as mudanças persistem e produzem "corpos inconclusos, desfeitos e refeitos, arquivos vivos de histórias de exclusão" (BENTO, 2006, p. 19).

Em "Problemas de Gênero", Butler (2020) apresenta o conceito de performatividade, discutindo o feminismo e a subversão da iden- 
tidade, enquanto em "Manifesto Contrassexual", Preciado (2017) discorre acerca da contrassexualidade e das práticas subversivas de identidade sexual. No primeiro desses dois livros, o conceito de "identidade" é devidamente ampliado quando a autora americana o troca por "identidades", subvertendo o próprio conceito do que é ser muIher. Ela também questiona os binarismos ao problematizar as concepções estruturalistas que dizem que o sexo é um dado biológico e o gênero é cultural. Ao invés disso, ela prefere dizer que o sexo é construído socialmente e o gênero é elaborado de forma performativa (BUTLER, 2020). Já na segunda referência, os estereótipos homem/mulher, homo/ hétero, etc. vão sendo desmanchados através da análise do dildo ${ }^{8}$. Por meio dele, Preciado (2017) expande as discussões sobre gênero, entendendo o corpo e a sexualidade como tecnologias, "sendo o sexo e o gênero dispositivos inscritos em um sistema tecnológico complexo" (PRECIADO, 2017. p. 23).

Vinculando as contribuições desses filósofos, exclusivamente ligadas ao corpo transgênero, com as teorias de Rancière (2012), obtenho um excelente campo teórico com potencial para desvendar lacunas e caminhos investigativos que estimulem 0 processo criativo empregado em uma produção artística que demonstre as características dissensuais presentes nos corpos trans/travestis, corpos que durante anos foram marginalizados e que, hoje, são objetos de minhas práticas na Arte Cinética.
A partir dessas referências, busco retratar essas existências sem a intenção de "transmitir mensagens, dar modelos ou contramodelos de comportamento ou ensinar a decifrar as representações" (RANCIÈRE, 2012, p. 55). Trabalhando, nessa perspectiva, no regime estético, que "consiste, sobretudo em disposições dos corpos, em recorte de espaços e tempo singulares que definem maneiras de ser" (RANCIÈRE, 2012, p. 55), de modo a apresentar artisticamente corporalidades que são verdadeiras produtoras de dissenso ambulantes, como disse o Prof. Dr. Gentil Porto Filho. Ele citou esse termo durante as aulas de Arte Contemporânea, eletiva do PPGDesign da UFPE' e disciplina para a qual este artigo foi confeccionado, como parte de seu processo avaliativo. Esse componente curricular procurava entender quais os modos de funcionalidade da arte contemporânea e suas relações com o cotidiano a partir dos regimes propostos por Rancière (2012).

Todavia não desisti de, por meio de minha arte, representar, para além do rergime estético, corpos que, como o meu, passaram por transformações para adequar-se à silhueta considerada feminina. Corporalidades que raramente são encontradas em espaços de arte, na propaganda, ou até mesmo nas ruas de qualquer cidade numa manhã de domingo ensolarada. Do mesmo modo, também não abandonei a vontade de, por meio dessas representações, estimular a compreensão de nossos comportamentos, hábitos, gírias e do modo
8 Em Manifesto Contrassexual Preciado (2017) faz uma análise histórica e etimológica da palavra dildo. Inicialmente ela introduz os "olisbos" que eram utilizados pelas mulheres na Cidade de Mileto, na Ásia Menor no Século III a.C, para compensar práticas sexuais que não contemplavam o prazer feminino ou naquelas ocasiões nas quais não havia a presença do homem. Seguindo em frente Preciado (2017) mostra a etimologia dos termos godemichi e godmicy ambos ligados à produção de prazer sexual desde o século $X V I$ ao $X X$. Feito isto ela chega ao "termo dildo que surge no século XVI e parece derivar do italiano diletto, que quer dizer prazer ou gozo" (PRECIADO, 2017, p. 198) e faz uma ligação interessante a esta investigação quando fala dos hermafroditas do século XVIII que se casavam com mulheres e usavam os dildos durante o sexo. Eles performavam o gênero masculino sem o conhecimento de suas esposas. Nesta época "o significado de dildo era "pênis artificial" ou "instrumento feito de cera, couro, borracha etc., que tem a forma de um substituto do pênis, e que as mulheres utilizavam como tal"'" (PRECIADO, 2017, p. 198-199). Por fim, baseando-se na cultura sexual lésbica, Preciado abandona os termos "consolo", "cinta-peniana" e "pinto de plástico" passando a usar a 
palavra "vibradores" após analisar os brinquedos sexuais presentes no seu estudo. Ela entende que estes não são imitações de um pênis feitas de plásticos. Ao contrário disto, eles parecem mais com mãos ou línguas prostéticas e conclui dizendo que a expressão "amor reflexivo" é um bom significado para a palavra dildo.

\begin{abstract}
9 Este artigo é produto dos estudos desenvolvidos neste componente curricular. Sua confecção tem origem na necessidade de criar um texto ao final da disciplina e a fala do Prof. surgiu durante as apresentações de meus seminários que sempre aproximavam os temas das aulas de minha pesquisa com gênero desenvolvida no PPGAV da UFPE/UFP
\end{abstract}

10 Este termo refere-se a semeIhança física que uma mulher trans alcança/possui em comparação com uma mulher cis. A passabilidade pode ser natural ou conquistada por meio de cirurgias, estética, tratamento hormonal ou mesmo maquiagem. Há um consenso entre alguns pesquisadores sobre a passabilidade estar ligada a sensação de segurança, uma vez que ao se passar por uma mulher cis, as mulheres trans estariam mais "seguras". Contudo não há garantia alguma disso, pois existem relatos de violência associada à descoberta da identidade trans em mulheres que são consideradas passáveis e devido a essa situação não contam a seus parceiros sobre sua identidade. de vida transexual. Logo, ao mesmo tempo em que pesquiso processos criativos estimulados pelo regime estético, também me interesso pelos regimes poético e ético.

\section{Chegaram elas, as produtoras de dissenso ambulantes}

Apesar de não ser o principal objetivo desse estudo, uma investigação como essa tem a representatividade sendo gestada em suas entranhas, afinal estou tratando de corpos historicamente marginalizados/apagados que nos últimos anos vêm lutando para incluir-se plenamente no corpo social, artístico e político. Essa presença se materializará por meio de imagens/esculturas oriundas de minhas práticas, e nesse sentido, destaco que o simples fato de uma mulher trans produzindo conhecimento científico a partir de um programa de mestrado já é um ato político a se considerar. Representa outro dissenso no meio acadêmico conservador, mas vamos em frente.

Eu poderia conduzir minhas investigações na pesquisa "Cadê as Travas Transcorpocinéticas?" sem incluir a política, e seguir pensando apenas na epistemologia da arte, o que, no lugar de artista visual, deixaria-me muito confortável. Porém, enquanto mulher transexual, preciso desenvolver o meu fazer artístico juntamente com os debates oriundos das esferas política e social, afinal por meio de representações ar- tísticas, outras mulheres podem sentir-se retratadas, presentes. Há vida neste trabalho e ele se alinha com o Transfeminismo que

\section{Pode ser definido como uma linha de pensamento e de prática feminista que redis- cute a subordinação mor- fológica do gênero (como construção psicossocial) ao sexo (como biologia), con- dicionada por processos his- tóricos, criticando-a como uma prática social que tem servido como justificativa para a opressão sobre quais- quer pessoas cujos corpos não estão conformes a nor- ma binária homem/pênis e mulher/vagina, incluindo-se ai homens e mulheres trans- gêneros (JESUS, 2014, p. 5).}

Essa exigência, praticamente um manifesto, é reflexo das relações de poder que estabelecem regras rígidas de comportamento e determinam qual existência é a correta e qual é a errada. Segundo Foucault (1979), ao investir no próprio corpo para satisfazer os desejos desse poder controlador, as pessoas tomaram consciência de si e de sua autonomia sobre as questões corporais. Como efeito desse controle, emergiu "inevitavelmente a reivindicação de seu próprio corpo contra o poder, a saúde contra a economia, o prazer contra as normas morais da sexualidade, do casamento, do pudor" (FOUCAULT, 1979, p. 146). Além dessa emancipação, a comunidade transsexual recorre a diversas transformações físicas e por meio de cirurgias, tratamentos hormonais e estéticos, persegue a pas- 
sabilidade ${ }^{10}$. Segundo Bento (2006), as mulheres trans mudam o corpo e lutam para se tornarem reais, pois, pelo menos durante muito tempo, o mundo ao seu redor tentou apagar as suas existências.

Seguindo nessa direção de luta e ativismo, a militante trans Indianara Siqueira, nascida em 1969, deu um "bug" no sistema jurídico ao retirar a camiseta durante a Marcha das Vadias na Cidade do Rio de Janeiro, no ano de 2012 (Figura 2). Segundo Altmayer e Portinari (2017), a partir desse gesto, ficou clara a diferença de tratamento dada às identidades binárias (homem/ mulher e cis/hétero) em detrimento daquelas que a desobedecem caminhando/performando para além das caixinhas heterocentradas (BUTLER, 2020; PRECIADO, 2017). No momento em que expôs os seios em público, Indianara "estremeceu as bases e normas que influenciam nas regras jurídicas para homens e mulheres, supostamente iguais perante a lei" (ALTMAYER; PORTINARI, 2017, p. 301).

Ela realizou essa ação performática diversas vezes e acabou sendo presa e autuada por desacato à autoridade. No processo, ficou clara a ambiguidade presente nas abordagens e na ação da justiça como um todo. Caso fosse presa, ela estaria tendo a sua identidade transfeminina reconhecida, pois estaria fazendo um topless, o que é proibido para as mulheres. Nesse momento seria aberto um precedente para todas as mulheres trans, contudo, deixaria claro o desequilíbrio jurídico existente entre homens e mulheres na questão do pudor. Disparidade que ficaria mais evidente caso fosse absolvida, uma vez que a justiça estaria reconhecendo que homens podem andar com o peitoral à mostra e mulheres não, o que demonstraria a assimetria presente entre os gêneros (ALTMAYER; PORTINARI, 2017).

Figura 2 - Registro da Performance de Indianara Siqueira na Marcha das Vadias de 2012 no Rio de Janeiro.

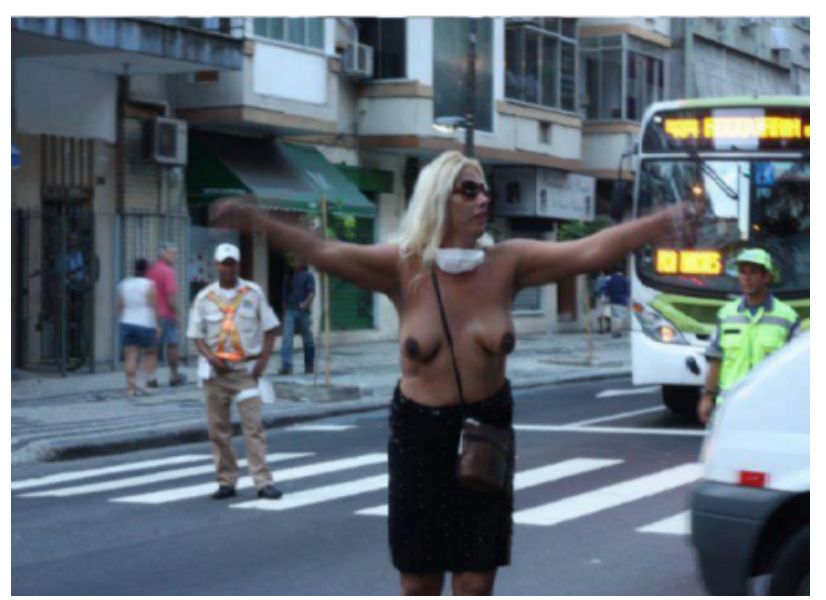

Fonte: Iconoclastia Incendiária"1

Problematizando ainda mais essa questão, desloco um pouco o foco para a questão da proibição dos seios à mostra, comparando-os com o apelo sexual existente nas propagandas que expõem os corpos de mulheres cisgêneras seminuas para vender cerveja e outros itens associados ao sexo masculino. Flausino (2002) usa o termo mulheres-espetáculo para referir-se àquelas modelos/atrizes que protagonizam comerciais de tv e "lá estão para serem consumidas, produtos de uma indústria cultural cujos objetivos mercadológicos são indiscutíveis" (FLAUSINO, 2002, p. 2). Esse tipo de imagem reafirma a normatização do gênero e a vende como
Disponível em: $<$ http://iconoclastia.org/2013/06/10/ indianara-siqueira-a-trans-que-pode-mudar-a-lei-brasileira/> Acessado em 04jan.2021 
Termo guarda-chuva que foi concebido na tentativa de dar conta de todos os corpos dissidentes de gênero. Entre eles as pessoas travestis, transexuais, crossdressers, drag-queens, drag-kings, não-binárias, etc. padrão a ser seguido, pois "sob todas as suas formas particulares de informação ou propaganda, publicidade ou consumo direto do entretenimento, o espetáculo constitui o modelo presente da vida social dominante" (DEBORD, 2003, p. 15).

Nessas imagens e vídeos mercadológicos, não costumamos ver mulheres trans protagonizando campanhas publicitárias. Esses corpos não interessam e não são ligados à publicidade sob o receio de associar as marcas neles exibidas à comunidade de pessoas trans, o que poderia acarretar a perda de vendas. Contudo, ao contrário da propaganda, os produtos artísticos incluem a transgeneridade ${ }^{12}$, principalmente se forem construídos por pessoas trans. Nesse sentido, os seios expostos de Indianara trazem à tona o papel da arte na expansão e criação de novas formas de saberes sobre os corpos (ALTMAYER; PORTINARI, 2017). Por meio das ações performativas de Indianara

Podemos entender o corpo como uma ferramenta que ao tomar consciência dos efeitos dos dispositivos que o atravessam e o constituem - família, escola, governos, medicina, psicologia, instâncias jurídicas e religião -, torna-se capaz de se apropriar e manipular esses mecanismos para se converter em uma máquina produtora de novos sentidos, novos territórios de ocupação contranormativos e insubordinados (ALTMAYER; PORTINARI, 2017, P. 301$)$.
Essa produção desobediente aparece na definição que Indianara dá para si. Ela designa-se como uma "pessoa normal de peito e pau" (ALTMAYER; PORTINARI, 2017, p. 302), desequilibrando/ignorando, por meio dessas palavras, as identidades baseadas na biologia. Com isso, suas ações, que embaralham as cartas do construto social cisheteronormativo, aproximam-se do pensamento de Rancière (2012) e demonstram que "a arte se torna disponível para que novas configurações do visível e do dizível sejam formuladas. Ou seja, se torna disponível para que novas partilhas do sensível possam ser por meio delas criadas" (DOS ANJOS, 2014, p. 18). Essas performances chamam a atenção para uma arte que "se torna capaz de interromper, ou de problematizar, as coordenadas sensoriais que qualquer um emprega para se relacionar com o mundo em que vive" (DOS ANJOS, 2014, p. 18). Sem esquecer que o fato desse tipo de reflexão estar sendo realizada por uma mulher trans faz uma grande diferença, dado que

A partilha do sensível é resultado de práticas de representação que constroem e reconstroem um sistema de evidências sensíveis que define a existência de um espaço de vida comum. Ou seja, práticas que estabelecem e delimitam um espaço que é reconhecido, hegemonicamente dentro de um grupo, como um equivalente sensível da realidade; práticas que delimitam o que pode ser visto, dito e plenamente 
entendido em uma conjuntura determinada (DOS ANJOS, 2014, P. 11).

Como as artistas trans sentem na pele o quanto é difícil habitar um corpo que não se enquadra com o gênero compulsório a elas atribuído, tornam-se elementos chaves nessas novas partilhas sensoriais. Dessa forma, o trabalho de arte acima citado representa um tipo de viés estético-político que pode nortear práticas artísticas que operem tensionando as dimensões miméticas e pedagógicas, mas não necessariamente abandonando-as por completo. Digo isso porque, apesar de, aparentemente, sua criadora não ter desejado representar nem ensinar coisa alguma aos espectadores, suas ações contêm questões ligadas à pedagogia e ao regime ético, afinal mostra a constituição desse corpo que nasceu com peitoral e não com mamas. Essa reflexão é baseada na pedagogia dos monstros de Cohen (2000) e numa das figuras anômalas de Foucault (2001), o monstro humano.

Cohen (2000) escreve sete teses com a finalidade de criar "um método para ler as culturas a partir dos monstros que elas engendram" (COHEN, 2000, p. 25). Assim como ele, Foucault (2001) analisa o surgimento das "anomalias", entre as quais estava o monstro humano, e seu funcionamento no Séc. XIX. Os dois autores apresentam inúmeras imagens e indivíduos que foram descritos como monstros e entre eles estavam aqueles considerados sexualmente diversos, uma vez que "a identidade sexual 'desviante' está igualmente sujeita ao processo de sua transformação em monstro" (COHEN, 2000, p. 35). Sob esta ótica, a imagem de uma mulher trans com os seios à mostra num sinal de trânsito poderia ser considerada monstruosa? Causaria dissenso? Certamente ela seria algo diferente, incomum, afinal, exceto nas praias onde o nudismo é permitido, não vemos mulheres sem camisas ou sem sutiãs andando naturalmente nas ruas das cidades. Logo, instituições como a Polícia puderam visualizar a referida performance sob uma ótica anômala, pois "qualquer tipo de alteridade pode ser inscrita através do corpo monstruoso, mas, em sua maior parte, a diferença monstruosa tende a ser cultural, política, racial, econômica ou sexual" (COHEN, 2000, p. 32). O embasamento para esse enquadramento encontra respaldo nas leis, instrumentos que já eram usados de forma equivocada a cerca de duzentos anos atrás quando, segundo Foucault (2001), o monstro humano, apesar de violar tanto as leis da natureza quanto da sociedade, era um fenômeno raro. Entretanto, apesar de ser uma infração

Ele não deflagra, da parte da lei, uma resposta que seria uma resposta legal. Podemos dizer que o que faz a força e a capacidade de inquietação do monstro é que, ao mesmo tempo em que viola a lei, ele a deixa sem voz. Ele arma uma arapuca para a lei que está infringindo. No fundo, o que $o$ 
13 A Intersexualidade é uma característica pertencente à pessoa intersexual, que, segundo Jesus (2012), é aquela "cujo corpo varia do padrão masculino ou feminino culturalmente estabelecido, no que se refere a configuração dos cromossomos, localização dos órgãos genitais (testículos que não desceram, pênis demasiado pequeno ou clitóris muito grande, final da uretra deslocado da ponta do pênis, vagina ausente), coexistência de tecidos testiculares e de ovários. A intersexualidade se refere a um conjunto amplo de variações dos corpos tidos como masculinos e femininos, que engloba, conforme a denominação médica, hermafroditas verdadeiros e pseudo-hermafroditas. O grupo composto por pessoas intersexuais têm-se mobilizado cada vez mais, a nível mundial, para que a intersexualidade não seja entendida como uma patologia, mas como uma variação, e para que não sejam submetidas, após o parto, a cirurgias ditas 'reparadoras', que as mutilam e moldam órgãos genitais que não necessariamente concordam com suas identidades de gênero ou orientações sexuais" (p. 25). monstro suscita, no mesmo momento em que, por sua existência, ele viola a lei, não é a resposta da lei, mas outra coisa bem diferente. Será a violência, será a vontade de supressão pura e simples, ou serão os cuidados médicos, ou será a piedade. Mas não é a lei mesma que responde a esse ataque que, no entanto, a existência do monstro representa contra ela. $O$ monstro é uma infração que se coloca automaticamente fora da lei, e é esse um dos primeiros equívocos. $\bigcirc$ segundo é que o monstro é, de certo modo, a forma espontânea, a forma brutal, mas, por conseguinte, a forma natural da contranatureza. É o modelo ampliado, a forma, desenvolvida pelos próprios jogos da natureza, de todas as pequenas irregularidades possíveis. E, nesse sentido, podemos dizer que o monstro é o grande modelo de todas as pequenas discrepâncias (FOUCAULT, 2001, p. 70-71).

Logo, percebo nesse recorte da análise foucaultiana da anomalia, que os bugs jurídicos gerados pelas "monstruosidades" já ocorriam desde o Séc. XIX, assim como ocorreu no caso de nossa performer. Ela pertence a uma categoria transfeminina que desde o período analisado por Foucault (2001), de acordo com os estudos de Leite Jr. (2009), passou a ser chamada de pseudo-hermafrodita da Medicina, abandonando tanto o olhar mágico e religioso que despertava quanto o lugar de maravilha da natureza para tornar-se 0 erro dessa. Ainda segundo o último autor, essa ancestral hermafrodita é a mãe e o pai das atuais identidades transgêneras. Sobre os hermafroditas desse tempo e os inúmeros exames realizados por médicos em busca da adequação de sua orientação sexual aos padrões da época e do entendimento de sua intersexualidade ${ }^{13}$, Foucault (2001) relata um caso bem particular ocorrido num período onde as figuras do indivíduo monstruoso e do desviante sexual se encontravam. Trata-se do Hermafrodita de Roven que, após ser submetido a inúmeros procedimentos corretivos, certamente dolorosos e humilhantes, pois ele vivia como um homem, acabou sendo o paciente que daria origem a necessidade de teorizar "um discurso sobre a sexualidade e, em todo caso, sobre a organização anatômica da sexualidade" (FOUCAULT, 2001, p. 88-89).

Esse desdobramento, certamente oriundo de uma situação humilhante para o paciente, assemeIha-se, de certa forma, àquilo que defende a pedagogia dos monstros em seu papel educacional, afinal não se pode negar que algum conhecimento foi gerado a partir dessa experiência, mesmo que ele tenha sido imensamente prejudicial às pessoas trans desde a sua origem. À sua época e com os preconceitos e normas estabelecidas orientando as suas práticas, aqueles médicos acabaram examinando a subjetividade do hermafrodita. Hoje, Cohen (2000, p.19) defende que, "no fundo, a questão da subjetividade diz respeito, sobretudo, ao cruzamento de fronteiras: entre o humano e 0 
não humano, entre cultura e natureza, entre diferentes tipos de subjetividade". Logo, diferente dos "doutores" do Séc. XIX, prefiro acreditar que "a 'existência' dos monstros é a demonstração de que a subjetividade não é, nunca, aquele lugar seguro e estável que a 'teoria do sujeito' nos levou a crer. As 'pegadas' do monstro não são a prova de que o monstro existe, mas de que o 'sujeito' não existe" (COHEN, 2000, p. 19).

Quando caminhou nas ruas ou ficou parada nos semáforos com os seios à mostra, Indianara marcou essas "pegadas" e em seu papel "monstruoso", arbitrariamente imposto pelas normas que ditam os papéis de gênero na contemporaneidade, ela, indiretamente, deixou claro que:
A 'pedagogia dos monstros' não desenvolve uma peda- gogia dirigida à formação de monstros nem uma pe- dagogia que utilize os mons- tros com fins formativos. A 'pedagogia dos monstros' recorre aos monstros para mostrar que o processo de formação da subjetividade é muito mais complicado do que nos fazem crer os pressu- postos sobre o 'sujeito' que constituem o núcleo das te- orias pedagógicas - críticas ou não (COHEN, 2000, p. 20).

Independente das questões pedagógicas acima apontadas, Indianara ansiava, por meio de sua performance, chacoalhar os padrões socialmente estabelecidos para os gêneros e as instituições que os organizam. Agentes que certamente não estavam presentes no momento da ação, mas que por meio da intervenção policial/judicial foram envolvidos diretamente no caso. Para Rancière (2012), o paradoxo existente entre esse tipo de atividade artística e a relação hierárquica de grupos sociais define a configuração do Regime estético da arte. Para exemplificar essa conexão que faço entre a nudez de uma travesti e o pensamento de Rancière (2012), recorro aos conflitos gerados pela convivência entre pessoas cisgêneras transfóbicas com pessoas transgêneras. Digo isso me baseando nas diversas gracinhas que escutei de pessoas que questionaram minha transmulheridade. Indivíduos que enxergam no meu corpo um "recipiente" pronto e perfeito para receber o ideal de homem, de macho, afinal eu nasci, biologicamente, perfeita. Então, porque "escolhi" ser assim? Porque "decidi" ser/viver uma/como muIher? Essa confusão causa dissenso na mente dessas pessoas que não entendem os conceitos de identidade de gênero. Do mesmo modo, um quadro, uma escultura ou uma performance pode incomodar e fazer alguém perguntar: por que esse museu está mostrando isso? Basta lembrar-se da Expo "Queer Museu". Além dessas questões, esses atos de Indianara tem um caráter contraprodutivo que busca "a produção de formas de prazer-saber alternativas à sexualidade moderna" (PRECIADO, 2017, p. 22). Seguindo a mesma direção, ou seja, o conceito de contraconduta de 
Foucault (2008), Altmayer e Portinari defendem que uma mulher trans expondo os seios em público cria um rompimento "com todos os vínculos que ela pode ter com o Estado, com as condutas estabelecidas, ao ampliar a discussão para uma ideia de direitos essenciais e fundamentais" (ALTMAYER; PORTINARI, 2017, p. 306). Privilégios que só podem ser obtidos com ações políticas que se alimentam desse romper de normas, pois "o consenso não é, nesse sentido, o objetivo da política, mas a sua morte" (DOS ANJOS, 2014, p. 12). Se nesse cenário "houver consenso, apaziguamento, calmaria, satisfação aparente [...] não há política. A política só existe, ao contrário, em meio ao dissentimento" (DOS ANJOS, 2014, p. 12).

Essa divergência se expande para a arte por meio do regime estético, como foi dito anteriormente. Meditando sobre essas questões e minhas práticas, entendo que uma escultura elaborada a partir de um corpo transexual (Figura 2) rompe as normas estabelecidas pelo que Preciado (2017) chama de contrato social heterocentrado. Nesse documento fictício, as "performatividades normativas foram inscritas nos corpos como verdades biológicas" (BUTLER, 2001 apud PRECIADO, 2017, p. 21). Sendo assim, a obra que pretendo produzir cria um dissenso ao expor no mesmo corpo um par de seios e um pênis, marcadores de gênero biologicamente definidos como pertencentes ao corpo feminino ou ao corpo masculino, respectivamente.
Mas Butler (2020) diz que a biologia também é um produto cultural. Então temos aqui uma situação perfeita para se pensar a política em Rancière (2012), uma vez que

Política não é jamais o espaço para o alcance de consensos, ou o espaço de convergência de pontos de vista diversos, como é comumente afirmado. Para Rancière, política só se faz e só existe por meio do "desentendimento", por meio da enunciação e da instauração do dissenso. Político nesse sentido, seria todo movimento de corpos, todo gesto feito, toda palavra dita, todo som emitido ou toda imagem criada que abre fendas e cria brechas nos consensos e nas convenções que organizam a vida em um determinado lugar e em um dado tempo (DOS ANJOS, 2014. p. 10-11).

Figura 2 - Esboços para móbile. Obra da Autora. Caneta hidrocor sobre papel. $20 \mathrm{x}$ $30 \mathrm{~cm}, 2020$

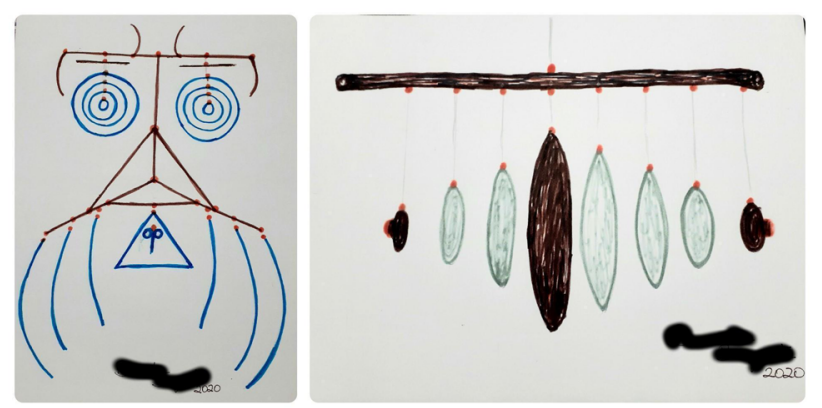

Fonte: a autora

Assim sendo, a pesquisa "Cadê as Travas Transcorpocinéticas?" martela essa consonância espaço-temporal, desatando nós muito bem dados no tecido social. Digo isso porque, tanto uma escultura cinética que represente corpos 
trans quanto o próprio desenvolvimento do conceito de Transcorpocinetismo rompem com a tradição abstrata da Arte Cinética que não apresenta, pelo menos nos livros clássicos de História da Arte, artistas mulheres criando móbiles (BAZANTE, 2020). Parece-me que muito menos tratando do gênero trans e problematizando política, pois quando se trata de representatividade estético-política, precisamos levar em conta quem está falando sobre 0 tema e de que forma fala, que dispositivos e mecanismos estão normatizando os discursos.

Temos aqui uma disputa de poderes estabelecida. De um lado, toda uma estrutura que historicamente determina o gênero desde o momento em que nascemos, e do outro, pessoas que a desobedecem ao olhar para o espelho e enxergar um corpo que difere do gênero compulsório que thes foi atribuído (BUTLER, 2020). Para elas, o reflexo ali contido não se encaixa no padrão cisnormativo atribuído-lhes compulsoriamente, já que a pergunta "é menino ou menina?" parece perder o sentido quando a resposta é dada baseada na genitália observada pela equipe médica.

É importante falar um pouco desse dado biológico, porque Butler (2020) traz essa questão bem no início de uma das obras mais relevantes para o movimento feminista pós-moderno. Apoiandose nos atritos que ocorrem dentro do próprio movimento, a partir de sua relação com a política, ela problematiza a teoria feminista ao dizer que "o próprio sujeito das mulhe- res não é mais compreendido em termos estáveis ou permanentes" (BUTLER, 2020, p.18) e complementa citando a existência de estudos que indicam "que é muito pequena, afinal, a concordância quanto ao que constitui, ou deveria constituir, a categoria das mulheres" (Ibidem).

Tensionando ainda mais essa linha, ela dá continuidade à discussão sobre representação, dizendo que:

Por um lado, a representação
serve como termo operacio-
nal no seio de um processo
político que busca estender
visibilidade e legitimidade às
mulheres como sujeitos polí-
ticos; por outro, a represen-
tação é a função normativa
de uma linguagem que re-
velaria ou distorceria o que é
tido como verdadeiro sobre
a categoria das mulheres
(BUTLER, 2020, p. 18).

Ou seja, com essa afirmação, a filósofa coloca em xeque o próprio modelo que muitas transsexuais e travestis têm como referência do que é feminino. Esse dissenso precisa estar presente nas práticas de arte, visto que uma produção que trate da representação de um corpo trans não pode sugerir um padrão de corpo. Como disse Rancière (2012), o modelo de eficácia estética rompe com o papel pedagógico destinado à arte em seu regime representativo. Esse dissenso pode ser percebido na Figura 3, um esboço que refiz ao perceber a necessidade de apresentar a multiplicidade de silhuetas e o movimento que pode ocorrer numa corporali- 
dade trans devido à aplicação de silicone na região dos quadris.

Ao desenvolver essa escultura, tenho em mente a crítica que Rancière faz aos artistas que "continuam a validar em massa modelos de eficácia da arte que talvez tenham sido abalados um século ou dois antes de todas essas novidades" (2012, p. 52-53). Ao tratar dos paradoxos da arte política, ele se refere, como foi dito no capítulo anterior, às produções artísticas que apresentam temas considerados revoltantes, performances/intervenções que são desenvolvidas fora do ateliê e outras que atacam diretamente o sistema dominante. Problematiza e questiona as práticas de artistas que elaboram esse tipo de arte, supondo uma tomada de posição por parte do espectador diante do que aprecia, visto que "não há evidências de que o conhecimento de uma situação provoque o desejo de mudá-la" (RANCIÈRE, 2012, p. 29). Porém, além de retratar o dissenso a partir de suas relações com o gênero, esse esboço também exemplifica a manipulação que ocorre nos corpos trans. Logo, vejo nele a coexistência dos dois regimes, ético e estético.

Juntamente como essa reflexão, enquanto desventura-se pela a tradição crítica, Rancière (2012) analisa duas imagens, uma produzida em 2005 e outra entre 19671972. Tratam-se de uma fotografia e de uma fotomontagem, respectivamente. A discussão sobre os aspectos relativos à arte e à política, presentes nessas produções, trazem à tona a heterogeneidade presen- te nas imagens e essa alteridade se tornará importantíssima para o meu processo criativo.

Figura 3 - Obra da Autora. Esboço para a região dos quadris. Caneta hidrocor sobre papel sulfite. $25 \times 30 \mathrm{~cm}, 2020$.

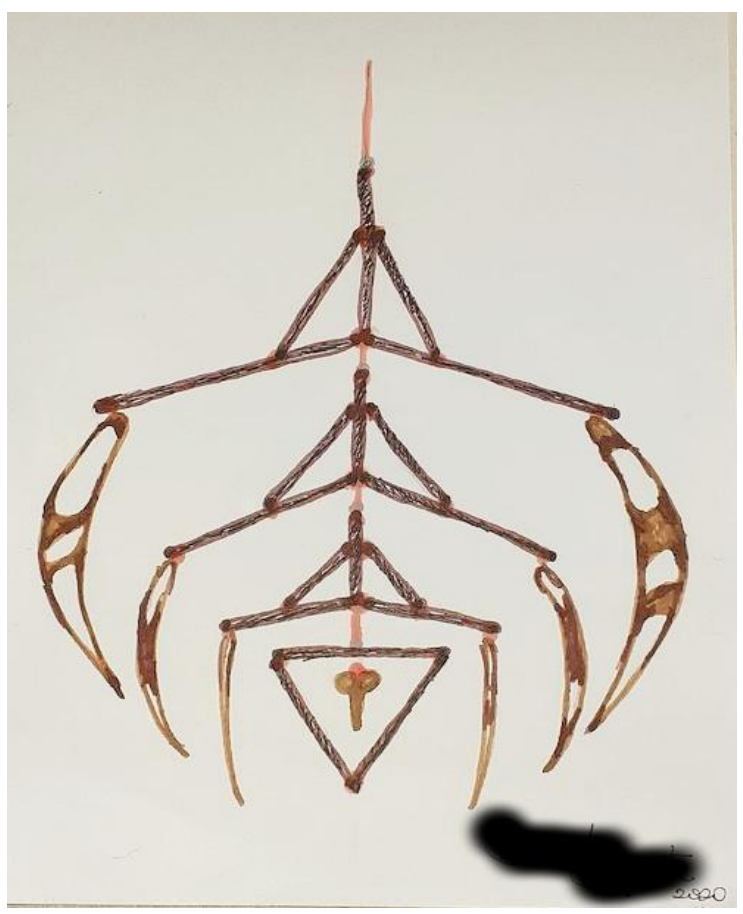

Fonte: a autora.

Por meio dos esboços e do protótipo apresentados, é possível ver a presença de elementos heterogêneos, conflituosos sobre uma mesma superfície. Estou falando de genitálias e dos seios, pois escolhi a região do torso como parte do corpo que pretendo apresentar, uma vez que nela estão contidos ora 0 pênis e o peitoral "masculinos", ora os seios e a vagina "femininos". Ao representar as duas genitálias, seios e peitorais no mesmo corpo, chamo atenção para a possibilidade de existência destes seres que possuem configurações divergentes dessa lógica binária (homem/pênis e muIher/vagina). Nesse caso, não proponho a presença simultânea das 
genitálias, pois não trato aqui do recorte intersexual, mas quero demonstrar, por meio do movimento, que esses órgãos podem mudar, afinal o sexo é construído cultural e o gênero é uma performance, como disse Butler (2020).

Figura 4 - Protótipo de seios. Obra da autora. Papelão, isopor, linha de crochê, gravetos e entremeios, dimensões diversas. 2020

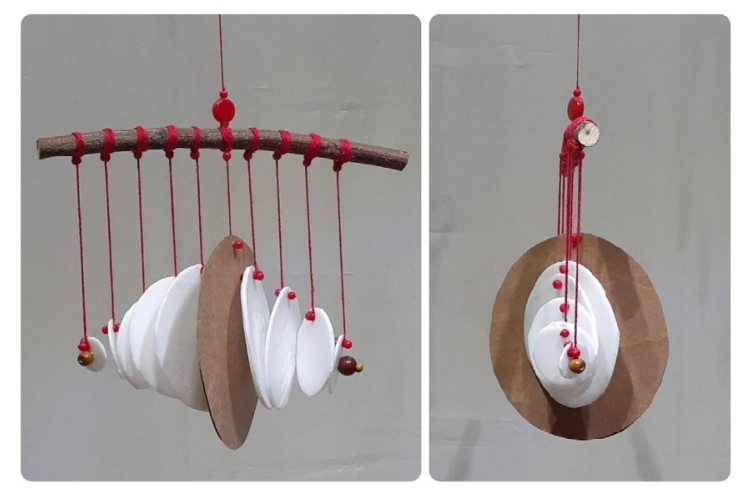

Fonte: A autora

Falando em heterogeneidade de elementos, o móbile "Protótipo dos seios" (Figura 4) retrata 0 andamento do processo criativo. É possível perceber que na escolha dos materiais utilizados eu elegi os gravetos como um suporte, assim como os ossos. Já o papel e o isopor fazem as vezes da pele e do silicone injetado, respectivamente. Essa peça exemplifica o dissenso que proponho com relação ao regime representativo, uma vez que os artistas cinéticos, historicamente, utilizaram a abstração como técnica para suas esculturas cinéticas e o metal como elemento de suporte e de movimento. Sendo assim, uma escultura móvel que se dispõe a retratar um seio utilizando gravetos, linha de crochê, isopor e papelão rompe com as regras de represen- tação desta linguagem, mas ainda assim representa um seio. Para além dessas discussões técnicas, com o seu movimento, o móbile pode não parecer uma mama. Sua forma perde-se quando a peça entra em movimento. Logo, a ação conética, nessa perspectiva, aproxima a peça do regime estético ao abandonar a representação do formato dos seios. Por fim, esse protótipo, assim como os esboços, contêm vestígios e tentativas de juntar, tensionar e problematizar os regimes de arte, segundo Rancière (2012), em suas relações com as questões de dissidência de gênero. Tarefa que continuarei a exercitar no decorrer da pesquisa desenvolvida no mestrado.

\section{Deambulações Finais}

Como foi dito no início deste artigo, essa busca começa a aproximar teóricos que tratam de arte política e dissidência de sexo e gênero, tendo como meio aglutinante a elaboração do conceito de Transcorpocinetismo e uma escultura cinética que represente o corpo transsexual.

Durante a leitura dos diversos livros e artigos que compuseram esta revisão, ficou clara a importância de meu trabalho no campo artístico-político-social ampliando, por meio da arte, as discussões sobre a corporalidade trans e sua inclusão no corpo social. Inclusão esta que vêm sendo diretamente atacada por governos conservadores que 
diariamente insistem no apagamento dessas existências. Como se isso fosse possível.

Para essas pessoas, diria que as imagens/palavras construídas a partir deste texto irão reverberar para além do ambiente acadêmico, pois a partir de estudos como esse, muitos artistas começam a entender a importância do papel social de suas práticas desobedientes, da criação de epistemologias que deem conta de construir o pensamento da comunidade LGBTIAP+.

Os dissensos ambulantes que criamos vão explodir e ultrapassar as grossas paredes históricas dos museus e as elegantes decorações das galerias de arte, diluindo-se no contexto social para assim transformarem-se em condutas artístico-assistenciais.

Para tal, entendo que esta investigação traz como caminho produtivo a junção dos regimes mimético e estético, uma vez que tradicionalmente me parece que as mulheres trans não foram, devidamente, contempladas pela produção escultórica, muito menos pela arte cinética. Dessa forma, além de suas particularidades estéticas, uma construção que apresente esses corpos precisa pensar em representatividade e mimetizar corpos historicamente invisibilizados.

Sendo assim, este estudo segue adiante investigando e criando formas de aproximar arte e política para num futuro breve atuar no campo social junto a ONGS como a AMOTRANS OU a NATRAPE, ambas de Pernambuco, que lidam diretamente com mulheres trans. Para isso, preciso entender como a arte afeta $\mathrm{O}$ assistencialismo e vice-versa. Sigo perguntando: como meu trabalho pode diluir-se e se misturar ao cotidiano da comunidade transgênera? Como a existência pode preceder a obra e os exemplos de que trata Bourriaud (2011) podem transformar-se em produções artísticas? Como construir móbiles a partir da corporalidade travesti sem cair nas armadilhas da sociedade do espetáculo? 


\section{Referências}

ALTMAYER, Carlos Guilherme Mace; PORTINARI, Denise Berruezo. As ações estético-políticas de enfrentamento direto de Indianara Siqueira, pessoa normal de peito e pau. Revista Periódicus, v. 1, n. 7, p. 300-312, 2017. Disponível em: https://portalseer.ufba.br/index.php/revistaperiodicus/article/ view/22280/14311. Acesso em: 20set.2020.

ARCHER, Michael. Arte Contemporânea: uma história concisa. São Paulo: Editora WMF Martins Fontes, 2012.

ARGAN, Giulio Carlo. Arte Moderna. São Paulo: Companhia das Letras, 1992.

BERBARA, Maria; FONSECA, Raphael. A transexualidade nas Artes Visuais. In: SILVA, Eloísio Alexsandro da. Transexualidade: princípios da atenção integral à saúde. São Paulo: Editora Santos, 2012.

BARRET, Cyril. Arte Cinética. In: STANGOS, Nikos. Conceitos da arte moderna. $2^{a}$ ed. Rio de Janeiro: Jorge Zahar Editor, 1991.

BAZANTE, Brenda Gomes. Corpocinetismo: relações entre a representação do corpo humano e esculturas cinéticas. Revista Apotheke, v. 6, n. 2, p. 191207, 2020. Disponível em: https://www.revistas.udesc.br/index.php/APOTHEKE/article/view/18337. Acesso em: 27set.2020.

BENTO, Berenice. A reinvenção do corpo: sexualidade e gênero na experiência transexual. Rio de Janeiro: Garamond, 2006.

BOURRIAUD, Nicolas. Formas de vida: a arte moderna e a invenção de si. São Paulo: Martins Fontes, 2011.

BUTLER. Judith. Problemas de gênero: feminismo e subversão da identidade. $19^{a}$ ed. Rio de Janeiro: Civilização Brasileira, 2020.

COHEN, Jeffrey Jerome. Pedagogia dos monstros: os prazeres e os perigos da confusão de fronteiras. Belo Horizonte: Autêntica, 2000.

DEBORD, Guy. A sociedade do espetáculo. Projeto Periferia, 2003.

DOS ANJOS, Moacir. Política da arte. Recife: Fundação Joaquim Nabuco, Diretoria de Memória, Educação, Cultura e Arte - MECA, Coordenação de Artes Visuais, 2014. 
FLAUSINO, Márcia Coelho. Mídia, sexualidade e identidade de gênero. In: XXV Congresso Brasileiro de Ciências da Comunicação. 2002. Disponível em: http://www.portcom.intercom.org.br/pdfs/751 1188ebb52dl4e626fladc072ebc44.pdf. Acesso em: 27set.2020.

FOUCAULT, Michel. Corpo utópico, as heterotopias. São Paulo: n-1 edições, 2013.

FOUCAULT, Michel. Microfísica do Poder. Rio de janeiro: Edições Graal, 1979.

FOUCAULT, Michel. Os anormais: curso no Collège de France (1974-1975). São Paulo: Martins Fontes, 2001.

FOUCAULT, Michel. Segurança, território e população. São Paulo: Martins Fontes, 2008.

GOMBRICH, E. H. A história da arte. Rio de Janeiro: LTC, 2013.

JESUS, Jaqueline Gomes de. Orientações sobre identidade de gênero: conceitos e termos. $2^{a}$ ed. Brasília, 2012.

JESUS, Jaqueline Gomes de et al. Transfeminismo: teorias e práticas. $1^{\circ}$ ed. Rio de Janeiro: Metanoia, 2014.

KRAUSS, Rosalind. Caminhos da escultura moderna. São Paulo: Martins Fontes, 1998.

LEITE JR., Jorge. "Que nunca chegue o dia que irá nos separar": notas sobre epistémê arcaica, hermafroditas, andróginos, mutilados e suas (des)continuidades modernas. Cad. Pagu, Campinas, n. 33, p. 285-312, Dec. 2009 Available from <http://www.scielo.br/scielo.php?script=sci_arttext\&pi$d=S 0104-83332009000200011$ \&lng=en\&nrm=iso > Acessado em: 02jan.2020

MAYRINK, Ana Luísa Pagani. Desafios metodológicos na leitura de Rancière com a apropriação da aparência por mulheres trans. In: MARTINO, Luís Mauro Sá; MARQUES, Ângela Cristina Salgueiro (Orgs.). Teorias da Comunicação: processos, desafios e limites. São Paulo: Plêiade, 2015.

PRECIADO, Paul Beatriz. Manifesto contrassexual: práticas subversivas de identidade sexual. São Paulo: n. 1 edições, 2017.

RANCIÈRE, Jacques. A partilha do sensível: estética e política. $2^{a}$ ed. São Paulo: EXO experimental org., Editora 34, 2009.

RANCIÈRE, Jacques. O espectador emancipado. São Paulo: Editora WMF Martins Fontes, 2012. 
Recebido em: 30/set/2020

Aceito em: 21/dez/2020 